\title{
Friction and Wear Study on Friction Pairs with a Biomimetic Non-smooth Surface of 316L Relative to CF/PEEK under a Seawater Lubricated Condition
}

\author{
Yingna Liang ${ }^{1,2}$ (]) Dianrong Gao ${ }^{1,3^{*}} \mathbb{D}$, Bo Chen ${ }^{1,3}$ and Jianhua Zhao ${ }^{1,3}$
}

\begin{abstract}
Current studies of a seawater axial piston pump mainly solve the problems of corrosion and wear in a slipper pair by selecting materials with corrosion resistance, self-lubrication, and wear resistance. In addition, an appropriate biomimetic non-smooth surface design for the slipper pair can further improve the tribological behavior. In this paper, 316 L stainless steel and CF/PEEK were selected to process the upper and bottom specimens, and the biomimetic non-smooth surface was introduced into the interface between the friction pair. The friction and wear tests were performed on a MMD-5A tester at a rotation speed of $1000 \mathrm{r} / \mathrm{min}$ and load of $200 \mathrm{~N}$ under seawater lubricated condition. The results indicate that the main friction form of the smooth surface friction pair corresponds to abrasive wear and adhesive wear and that it exhibits a friction coefficient of $0.05-0.07$, a specimen temperature of $56^{\circ} \mathrm{C}$, a high wear rate, and surface roughness. Pits on the non-smooth surface friction pairs produced hydrodynamic lubrication and reduced abrasive wear, and thus the plowing effect is their main friction form. The non-smooth surface friction pairs exhibit a friction coefficient of $0.03-0.04$, a specimen temperature of $48^{\circ} \mathrm{C}$, a low wear rate, and surface roughness. The study has important theoretical significance for enriching the lubrication, friction, and wear theory of a seawater axial piston pump, and economic significance and military significance for promoting the marine development and the national defense military.
\end{abstract}

Keywords: Biomimetic non-smooth surface, 316L, CF/PEEK, Seawater lubrication, Friction and wear

\section{Introduction}

Various advantages of seawater including cleanliness, safety, and convenience promote the development of seawater hydraulic transmission system. However, when compared with mineral oil, seawater exhibits slightly different physical and chemical properties including low viscosity, poor lubricity, high electric conductivity, and vaporization pressure. The seawater axial piston pump is the core power element of seawater hydraulic transmission systems. The slipper pair of the pump is extremely vulnerable to corrosion and abrasion while operating in

\footnotetext{
*Correspondence: gaodr@ysu.edu.cn

${ }^{1}$ School of Mechanical Engineering, Yanshan University,

Qinhuangdao 066004, China

Full list of author information is available at the end of the article
}

the seawater environment. Previous studies extensively examined materials with corrosion resistance, anti-wear, and self-lubrication for friction pairs and concluded that engineering plastics, engineering ceramics, surface engineering materials, and special corrosion resistant alloys comprise the four major types of materials with the aforementioned properties [1-8]. The use of new materials to a certain extent enhances the tribological performance and prolongs the service life of the slipper pair in seawater axial piston pump. Conversely, the traditional design of hydrostatic bearing for slippers leads to large leakage due to the low viscosity of seawater. Therefore, the biomimetic non-smooth surface effect, which is inspired by the natural biological body surface, is introduced into a slipper pair based on selecting the optimal matching materials. The study explores the mechanism of lubrication, 
drag reduction, and wear resistance of the biomimetic non-smooth surface that is extremely important for the practical application of seawater axial piston pump and other seawater hydraulic components.

In 1966, Hamilton et al. [9] observed that the microirregularities on the surfaces of rotary-shaft seal produced hydrodynamic pressure and created load carrying capacity. Anno et al. [10] concluded that the introduction of micro-asperities constitutes a method to lubricate mechanical face seals and parallel rotating thrust bearings. Extant research stagnated in the following three decades and subsequently gained momentum in 1996 when Etsion's group published a study on surface texturing [11]. They used the incompressible two-dimensional Reynolds equation in conjunction with the Half-Sommerfeld cavitation boundary condition to mathematically investigate mechanical seals with hemispherical dimples on mating surfaces. Subsequently, they produced a few seals with micro-dimples by using laser surface texturing (LST) for tests and indicated that each micro-dimple serves either as a micro-hydrodynamic bearing in cases with full or mixed lubrication, a micro-reservoir for a lubricant in cases of starved lubrication, or a micro-trap for wear debris in either lubricated or dry sliding [12, 13]. Tala-Ighil et al. [14] investigated journal bearing characteristics modellization for both cases of texture presence or absence onto the bearing surface. The textured bearing performance enhancement passed essentially by a minimum film thickness and a friction torque improvement through an appropriate surface texture geometry and right texture distribution. Scaraggi et al. [15] arranged a square lattice of micro-holes on surfaces with the same textured area density albeit different diameters and different depths by using LST, measured the friction coefficient on a range of sliding velocities from the mixed lubrication regime to the hydrodynamic lubrication regime, and indicated that the depth and the diameter of micro-holes significantly influenced the amount of friction reduction at the interface. Ren et al. $[16,17]$ established the basic theory of a non-smooth surface and applied the desorption and drag reduction technology to agricultural machinery parts. Han et al. [18, 19] applied biomimetic non-smooth theory in the preparation of gear and suggested that the wear resistance of gear with non-smooth units of ellipsoidal, groove or grid on tooth surfaces increased by 3-5 times, the service life was prolonged by 3-4 times although the cost only increased by $15 \%-40 \%$ when compared with those of smooth surface gear. Hua et al. [20-22] investigated the effect of discriminating partition laser surface micro-texturing on engine comprehensive performance. A significant reduction in specific fuel consumption of the engine was observed with the laser micro-textured cylinders compared to that of the standard cylinder. Shen et al. [23, 24] conducted a series of bench tests to investigate the frictional performance of flat piston ring prototype with various micropockets, and found that the pocket area ratio and depth had a major influence on tribological behaviors.

The application of biomimetic non-smooth surface in seals, journal bearings, cylinder liners, and gear inspires the surface design of a slipper pair in seawater axial piston pump. Specifically, 316L stainless steel and CF/PEEK are selected as matching materials to process several friction pairs with biomimetic non-smooth surface. Subsequently friction and wear tests under seawater lubricated condition are performed, the parameters of friction coefficient, specimen temperature, wear rate, and worn surface morphology of the friction pairs with biomimetic non-smooth surface are analyzed, and the friction and wear mechanism are investigated.

\section{Experimental Details}

\subsection{Materials and Specimens}

The upper specimen is composed of $316 \mathrm{~L}$ stainless steel, which is a cost-effective metal material in water hydraulic industry due to its excellent plasticity, toughness, and corrosion resistance. The chemical constituents of 316L stainless steel are $(w / \%): C \leq 0.03 ; \mathrm{Si} \leq 1.0 ; \mathrm{Mn} \leq 2.0$; $\mathrm{S} \leq 0.03 ; \mathrm{P} \leq 0.045$; Cr 16.0-18.0; Ni 10.0-14.0; Mo 2.03.0. The physical and mechanical properties are given in Table 1.

The bottom specimen is composed of CF/PEEK, which is a poly aryl ether ketone polymer compound reinforced with carbon fibers and exhibits outstanding corrosion resistance, self-lubrication, and wear resistance. The physical and mechanical properties are summarized in Table 2.

Three different types of friction pair and their original surface morphologies are shown in Figure 1. There are two convex cylinders $(\Phi 10 \mathrm{~mm} \times 2 \mathrm{~mm})$ on the ring surface with an outer diameter of $40 \mathrm{~mm}$ and an inner diameter of $20 \mathrm{~mm}$ for the upper specimen. The bottom specimen exhibits a diameter of $43 \mathrm{~mm}$ and a

\begin{tabular}{|c|c|c|}
\hline Property & Standard & Value \\
\hline Density $\rho\left(\mathrm{g} / \mathrm{cm}^{3}\right)$ & GB/T 20878-2007 & 8.03 \\
\hline Elastic modulus $E(\mathrm{GPa})$ & & 206 \\
\hline Brinell hardness $H B$ & & 230 \\
\hline Elongation $\delta(\%)$ & & 30 \\
\hline Thermal conductivity $\lambda(W /(m \cdot k))$ & & 16.3 \\
\hline Thermal expansion coefficient $a\left(10^{-6}{ }^{\circ} \mathrm{C}\right)$ & & 16.0 \\
\hline Tensile strength $\sigma_{b}(\mathrm{MPa})$ & & 620 \\
\hline Yield strength $\sigma_{s}(\mathrm{MPa})$ & & 310 \\
\hline
\end{tabular}


Table 2 Physical and mechanical properties of CF/PEEK

\begin{tabular}{lll}
\hline Property & Standard & Value \\
\hline Density $\rho\left(\mathrm{g} / \mathrm{cm}^{3}\right)$ & ISO 1183 & 1.4 \\
Water absorption $\left(25^{\circ} \mathrm{C}, 24 \mathrm{~h}\right) \mathrm{W}(\%)$ & ISO 62 & 0.06 \\
Rockwell hardness HRR & ASTM D785 & 107 \\
Heat deflection temperature $H D T\left({ }^{\circ} \mathrm{C}\right)$ & ASTM D648 & 315 \\
Thermal expansion coefficient $a\left(10^{-5}{ }^{\circ} \mathrm{C}\right)$ & ASTM D696 & 1.5 \\
Tensile strength $\left(23^{\circ} \mathrm{C}\right) \sigma_{b}(\mathrm{MPa})$ & ISO 527-2/1B/50 & 220 \\
Bending strength $\left(23^{\circ} \mathrm{C}\right) \sigma_{b b}(\mathrm{MPa})$ & ISO 178 & 298 \\
Compression strength $\left(23^{\circ} \mathrm{C}\right) \sigma_{b c}(\mathrm{MPa})$ & ASTM D695 & 240 \\
\hline
\end{tabular}

Note: All data in tables are provided by Junhua co. LTD, Changzhou, Jiangsu China

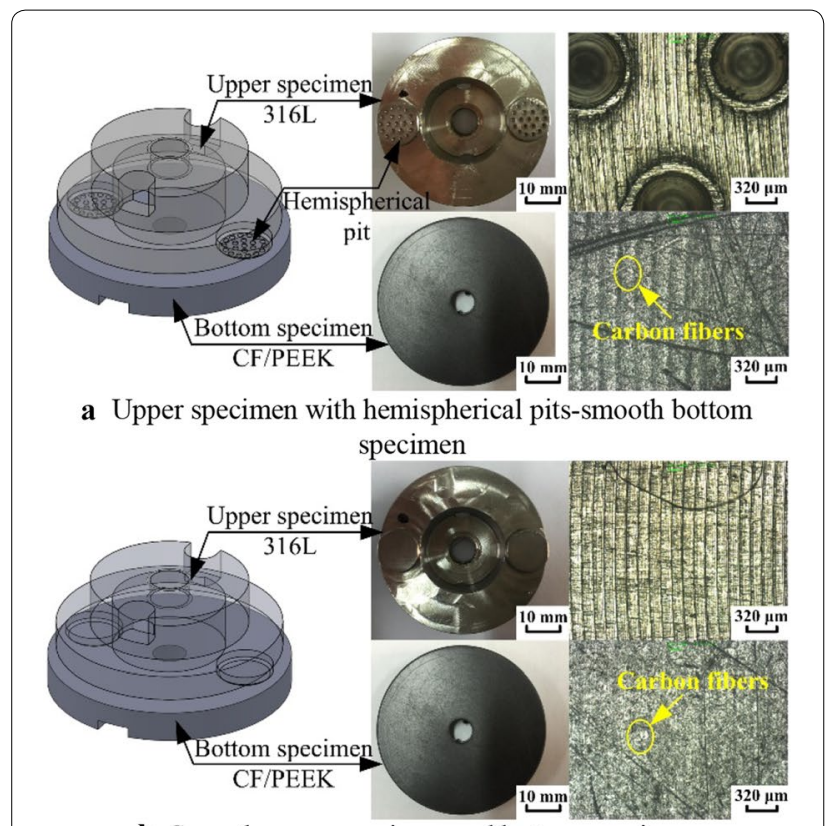

b Smooth upper specimen and bottom specimen

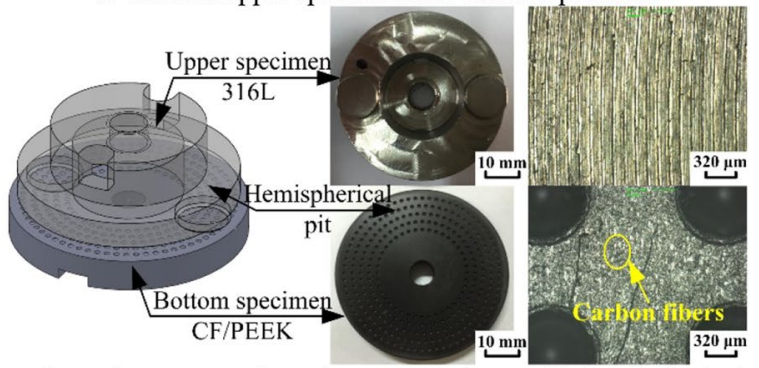

c Smooth upper specimen-bottom specimen with hemispherical pits

Figure 1 Configuration and original surface morphology of friction pairs

height of $6 \mathrm{~mm}$. In order to investigate the tribological mechanisms and properties of the millimeter-scale pits, hemispherical pits with a radius of $0.5 \mathrm{~mm}$ which had good load carrying capacity shown from the previous numerical simulation [25] were processed on the surfaces of specimens. Figure 1(a) shows the first type of friction pair with non-smooth surface in which the upper specimen includes 1, 6, 14 hemispherical pits respectively equispaced at the center, the $\Phi 3.6 \mathrm{~mm}$ circle, the $\Phi 7.2 \mathrm{~mm}$ circle on the surface of each convex cylinders. Figure 1(c) shows the other type of friction pair with non-smooth surface in which the bottom specimen includes 40, 48, 55, 62, and 68 hemispherical pits respectively equispaced at the circles corresponding to $\Phi 22 \mathrm{~mm}, \Phi 26 \mathrm{~mm}, \Phi 30 \mathrm{~mm}, \Phi 34 \mathrm{~mm}$, and $\Phi 38 \mathrm{~mm}$ on the surface. Figure 2 shows the 3D topographies of the smooth surface and hemispherical pit.

\subsection{Lubricating Medium}

Natural seawater used as lubricating medium in the friction and wear tests was obtained from the coastal area of Qinhuangdao. The $\mathrm{PH}$ value is 7.2 and the salinity is $2.983 \%$, which is measured based on the GB 17378.4-2007 standard [26]. The microorganisms in seawater were disinfected first and subsequently the seawater was kept for $24 \mathrm{~h}$ and filtered by filter paper to remove redundant crystalline salt and impurities.

\subsection{Friction and Wear Test}

Prior to tests, all the specimens were cleaned in an acetone solution for $20 \mathrm{~min}$ via an ultrasonic cleaning instrument (DS-1510DTH, Sonxi Manufacturing, Qingpu,

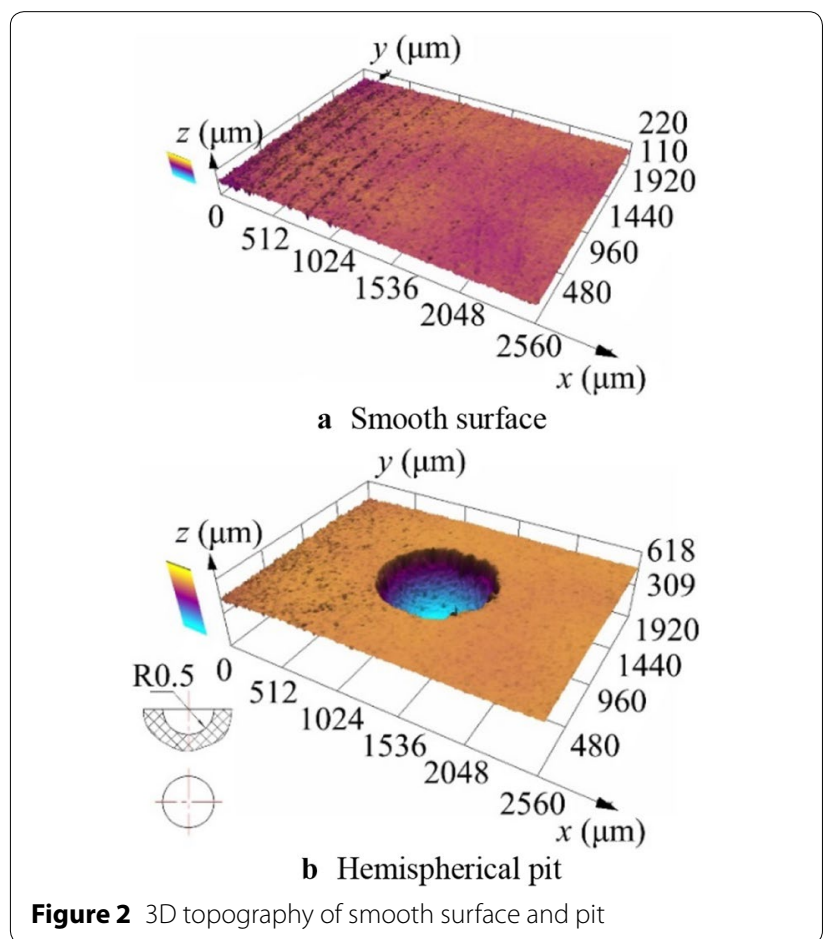


Shanghai China) and dried in air. Subsequently, the electronic balance (FA1004, Liangping Manufacturing, Songjiang, Shanghai China) with an accuracy of $0.1 \mathrm{mg}$ was used for weighing. Each specimen was weighed thrice, and the average value was considered as the final value to ensure the accuracy of the measurement. The original surface morphologies of the specimens were observed via a confocal laser microscope (OLS 3100, Olympus Manufacturing, Shinjuku-ku, Tokyo Japan) and scanning electron microscope (S-3400N, Hitachi Manufacturing, Chiyoda-ku, Tokyo Japan).

The tests were conducted on a friction and wear tester (MMD-5A, Chenda Manufacturing, Jinan, Shandong China) as shown in Figure 3. The upper specimen was mounted on the main shaft through the upper specimen fixture and was driven by the servo motor to rotate. The bottom specimen was fixed on the column through the bottom specimen mounting base and was lifted and loaded by the hydraulic system. The upper specimen fixture includes an adaptive function that ensures that the upper and bottom specimen surfaces are always in parallel contact during the sliding process. The relative movement between the two convex cylinders of the upper specimen and bottom specimen is similar to the movement pattern of a slipper pair. Prior to each test, $260 \mathrm{~mL}$ of seawater was injected into a plexiglass seawater box to ensure that the entire sliding process of the friction pairs was in seawater lubrication state. The tests were performed with a rotation speed of $1000 \mathrm{r} / \mathrm{min}$, a load

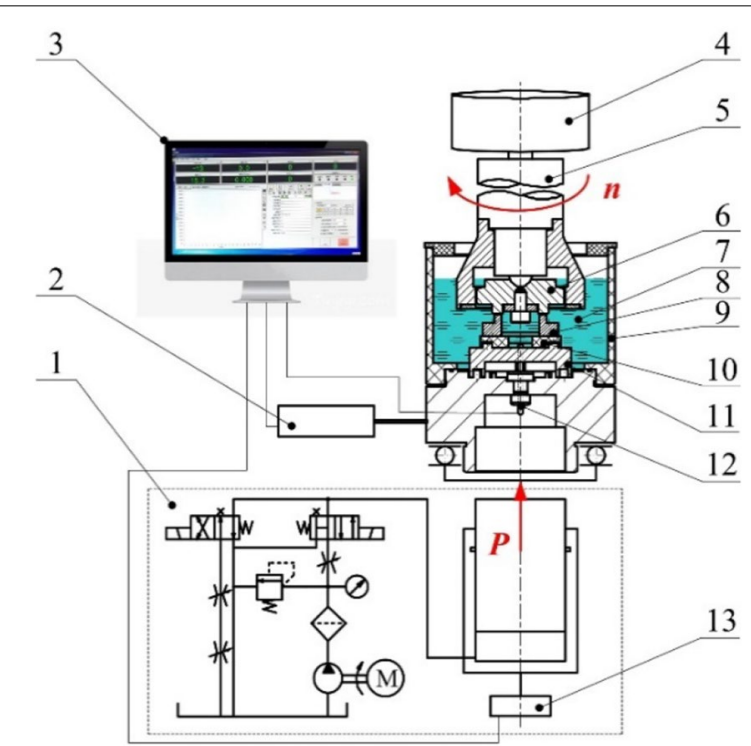

Figure 3 Schematic diagram of MMD-5A friction and wear tester. 1. Hydraulic system; 2. Tension sensor; 3. Computer; 4. Servo motor; 5. Main shaft; 6. Upper specimen fixture; 7. Seawater; 8. Upper specimen; 9 . Seawater box; 10. Bottom specimen; 11. Bottom specimen mounting base; 12 . Temperature sensor; 13. Pressure sensor of $200 \mathrm{~N}$, and a time duration of $5400 \mathrm{~s}$, according to the practical working condition of seawater axial piston pumps and the hardness of CF/PEEK. The friction coefficient and specimen temperature were monitored and recorded via sensors in real time. Each group of friction test was repeated thrice to establish confidence.

After the tests, all the specimens were cleaned, dried, weighed, and their surface was observed again.

\section{Results and Discussion}

\subsection{Analysis of Test Parameters}

Figure 4 presents the variation of friction coefficient of three different types of friction pairs with respect to the test time. The friction coefficient of the smooth surface friction pair decreases rapidly from 0.05 to 0.029 in the first $300 \mathrm{~s}$. After holding the value for a period, it increases to 0.06 at $2500 \mathrm{~s}$ and maintains the value until the end of test. The friction coefficient of two non-smooth surface friction pairs decreases from 0.034 and 0.042 to 0.029 and 0.032 in the first $200 \mathrm{~s}$, respectively. During the remaining time, the friction coefficient of upper with hemispherical pits-bottom smooth friction pair increases slowly to 0.04 , and that of upper smooth-bottom with hemispherical pits friction pair maintains between 0.03-0.036. It is observed that all three friction processes experience an initial running-in period of $200-300 \mathrm{~s}$ during which the relative movement is more intense and subsequently tends to be stable. The sudden increase in the friction coefficient of smooth surface friction pair indicates that the friction form changed during the test.

Figure 5 shows the average friction coefficient and its standard deviation of three different types of friction pairs. The average friction coefficients of two nonsmooth surface friction pairs are lower than those of the smooth surface friction pair with drops of $23.4 \%$ (the upper with hemispherical pits-bottom smooth friction pair) and $24.7 \%$ (the upper smooth-bottom with hemispherical pits friction pair), respectively. The order of standard deviation corresponds to the smooth surface friction pair $>$ the upper with hemispherical pits-bottom smooth friction pair $>$ the upper smooth-bottom with

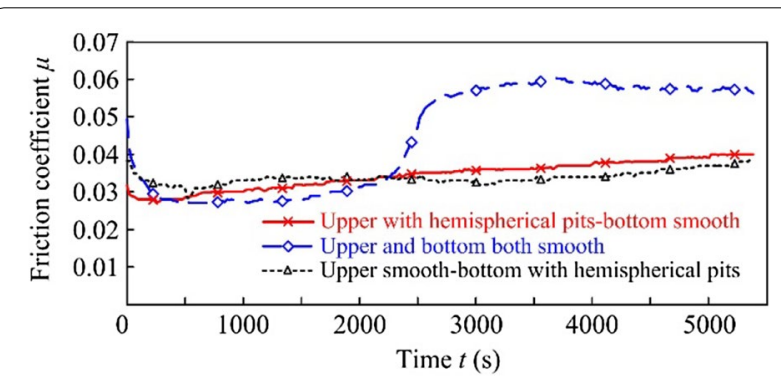

Figure 4 Variation of the friction coefficient with test time for different types of friction pairs 


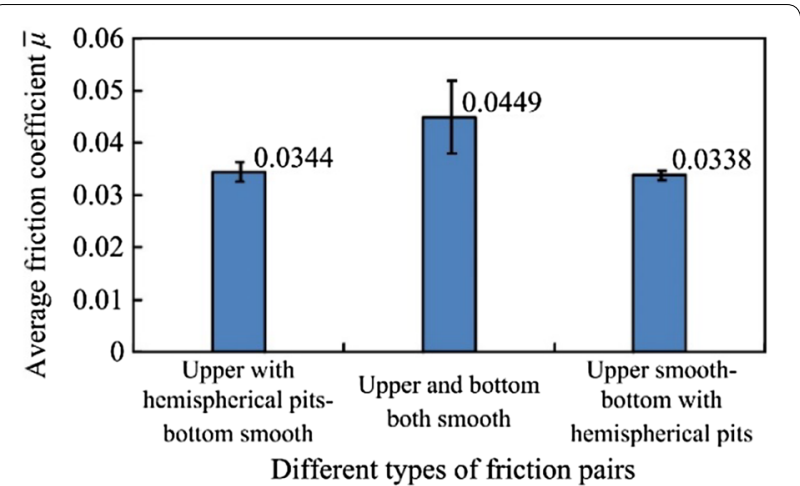

Figure 5 Average friction coefficient for different types of friction pairs

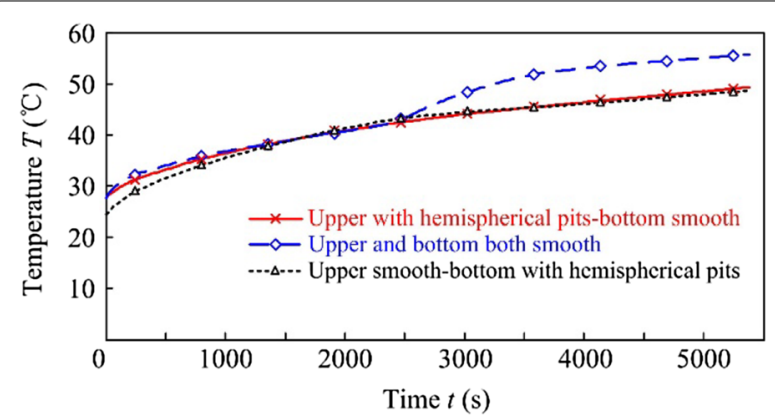

Figure 6 Variation of the bottom specimen temperature with test time for different types of friction pairs

hemispherical pits friction pair. It indicates that the friction coefficient and its fluctuation decrease due to the hydrodynamic effect produced by the non-smooth surface during sliding under seawater lubricated condition. The most optimal performance is exhibited by the upper smooth-bottom with hemispherical pits friction pair.

As shown in Figure 6, all the bottom specimen temperatures of three different types of friction pairs present an increasing trend with test time during the whole friction process. The bottom specimen temperature of smooth surface friction pair increases from $27.8^{\circ} \mathrm{C}$ at the beginning to $43{ }^{\circ} \mathrm{C}$ at $2500 \mathrm{~s}$, and subsequently gradually increases to $56{ }^{\circ} \mathrm{C}$ at the end after a low bump. The temperature curves of two non-smooth surface friction pairs coincide with each other and increase from $27.6{ }^{\circ} \mathrm{C}$ and $24.3{ }^{\circ} \mathrm{C}$ at the beginning to $43{ }^{\circ} \mathrm{C}$ at the end. The temperature of upper smooth-bottom with hemispherical pits friction pair is lower. A comparison with Figure 4 indicates a synergetic effect on the variation of bottom specimen temperature with the friction coefficient. An increase in the friction coefficient increases the microscopic friction and wear behavior between the contact surfaces, increases the friction energy consumption, and increases the rise in surface temperature $[4,27]$.
As shown as Figure 7, the order of average bottom specimen temperature corresponds to the smooth surface friction pair > the upper with hemispherical pits-bottom smooth friction pair $>$ the upper smooth-bottom with hemispherical pits friction pair while that of standard deviation corresponds to the smooth surface friction pair $>$ the upper smooth-bottom with hemispherical pits friction pair > the upper with hemispherical pits-bottom smooth friction pair. A similar variation in the average friction coefficient is also obtained when compared with Figure 5.

Based on the mass loss of the specimens before and after the test, the volume loss per meter per mega pascal was calculated, and this is termed as the wear rate. Given a certain number of pits distributed on the surface, the wear rate of non-smooth surface specimen was calculated based on the actual contact area. As shown in Figure 8, the wear rates of the upper and bottom specimens of three different types of friction pairs are all positive, and this indicates a reduction in the mass of all

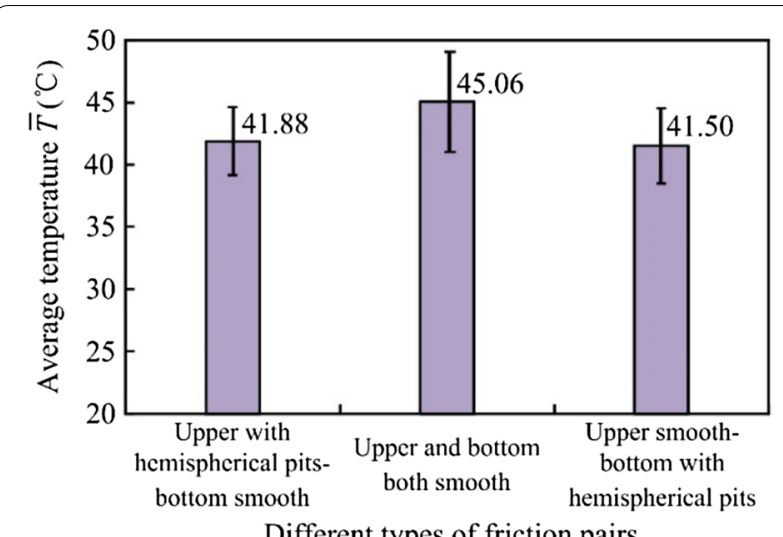

Different types of friction pairs

Figure 7 Average bottom specimen temperature for different types of friction pairs

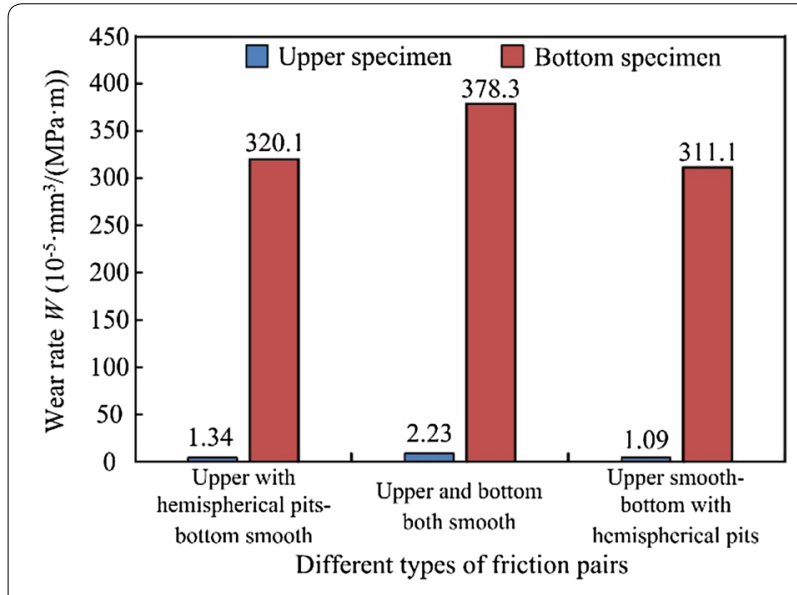

Figure 8 Wear rate of specimen for different types of friction pairs 
specimens after the test. The reduction of bottom specimen is significantly higher than that of upper specimen because the hardness of bottom specimen CF/PEEK is significantly lower than that of upper specimen 316L. A comparison of the three friction pairs indicates that the wear rate of smooth surface friction pair is evidently higher than those of two non-smooth surface friction pairs, and the upper smooth-bottom with hemispherical pits friction pair exhibits the lowest value. It presents the same variation with the friction coefficient and the bottom specimen temperature.

\subsection{Analysis of Worn Surface}

Figures 9, 10, 11 show the worn surface morphologies of three different types of friction pairs. When compared with the original morphologies prior to the test (Figure 1), a few slight scratches and evident color-deepening were observed on the worn surface of all upper specimens 316L. These correspond to the polished effect and significant grooves along the sliding direction on the worn surface of all the bottom CF/PEEK specimens.

This in combination with the analysis in Figure 4 indicates that the surface rough peaks of $316 \mathrm{~L}$ and CF/ PEEK contacted and embedded with each other after the test commenced under a normal load. Fierce collisions occurred between the rough peaks when the upper and bottom specimens began sliding relatively, and this generated a higher friction coefficient. The hardness of 316L exceeds that of CF/PEEK, and thus the rough peaks of
CF/PEEK were gradually flattened until the running-in period ended. In the subsequent sliding, the rough peaks of 316L began to embed in the surface of CF/PEEK and push its material and caused it to flow plastically and ploughed out several grooves, and this is termed as the plowing effect. The upper specimen only exhibits two convex cylindrical bottom surfaces joining in friction, and thus the pin-disk motion mode is more beneficial for seawater to establish a boundary lubrication film between the friction pair surfaces, reduce the specimen surface temperature, and scour the wear debris [28]. Hence, the friction coefficient is low in the early stage of the test. The amount of wear debris between the friction pair surfaces gradually increased, and thus abrasive wear began to occur. When the interfacial bonding strength exceeds the intermolecular bonding strength of CF/PEEK [29], the surface material of CF/PEEK is transferred to the surface of $316 \mathrm{~L}$, and this is termed as adhesive wear [30].

The surface material transfer of CF/PEEK caused by adhesive wear is also demonstrated by the EDS analysis of worn surface of 316L upper specimen in Figure 12. The results of element energy spectrum analysis in Figure 12(a) indicate that the mass fraction of $C$ increases to $5.41 \%$ and that its source corresponds to the carbon fibers in bottom specimen CF/PEEK. The SEM image in Figure 12(b) clearly shows that a dark sheet adhesion adheres to the surface of $316 \mathrm{~L}$, and this corresponds to the carbon fiber that is transferred from the surface of CF/PEEK in combination with the surface scanning

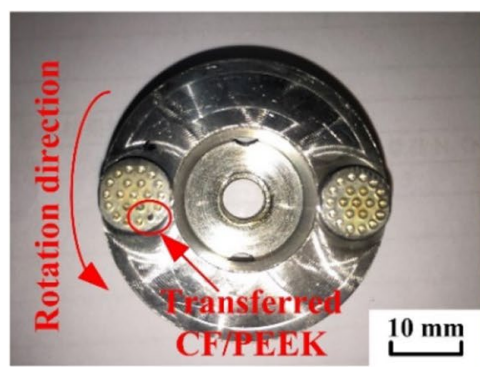

a Photograph of $316 \mathrm{~L}$

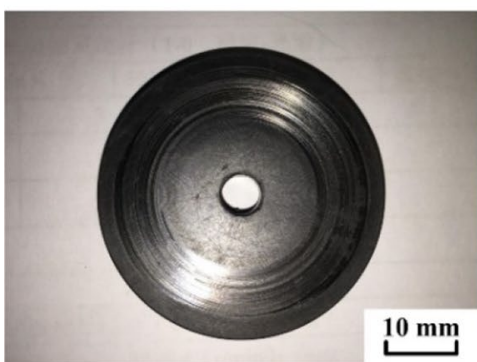

d Photograph of CF/PEEK

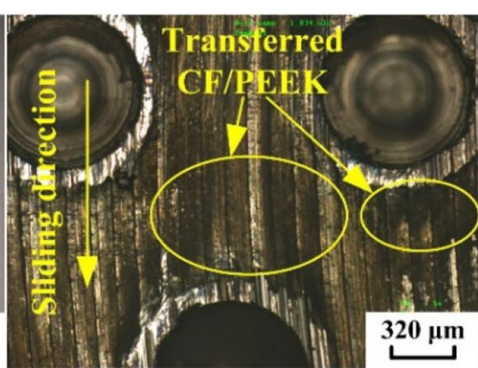

b LCM image of $316 \mathrm{~L}$

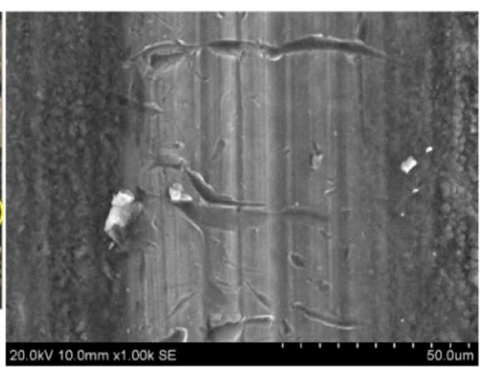

c SEM image of $316 \mathrm{~L}$

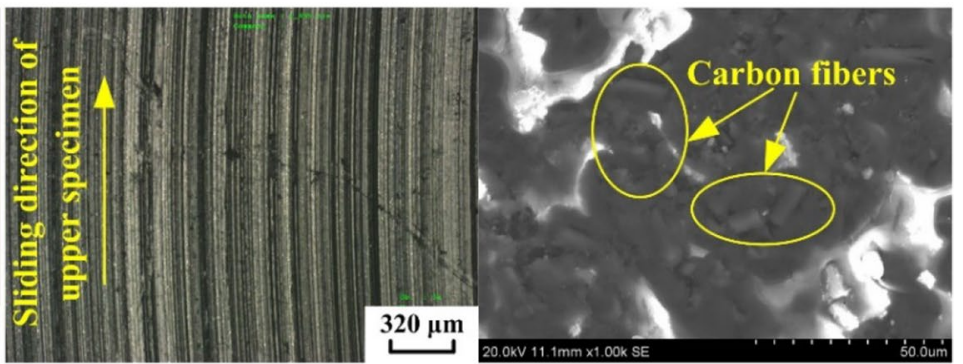

e LCM image of CF/PEEK

f SEM image of CF/PEEK

Figure 9 Worn surface morphology of the upper with hemispherical pits-bottom smooth friction pair 


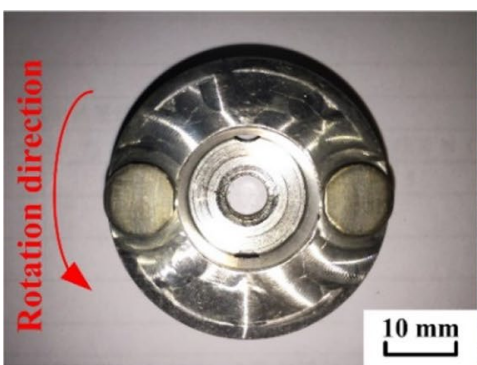

a Photograph of $316 \mathrm{~L}$

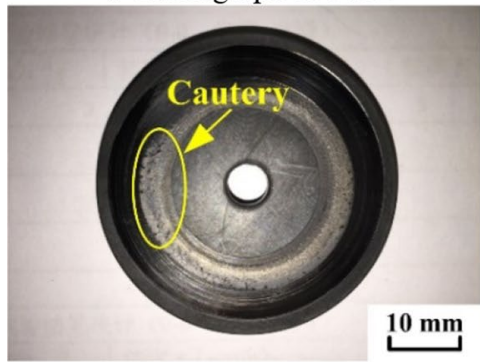

d Photograph of CF/PEEK

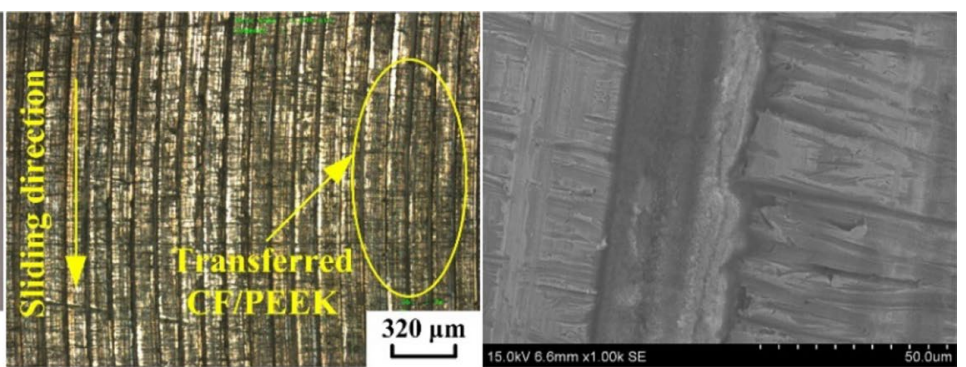

b LCM image of 316L c SEM image of 316L

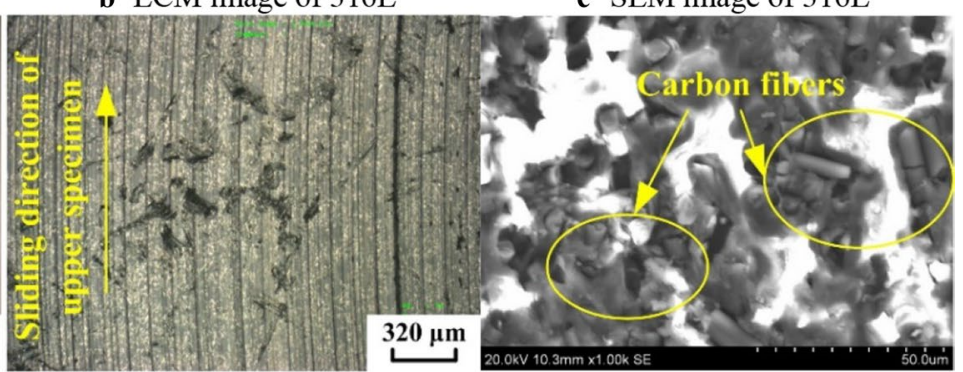

e LCM image of CF/PEEK

f SEM image of CF/PEEK

Figure 10 Worn surface morphology of the smooth surface friction pair

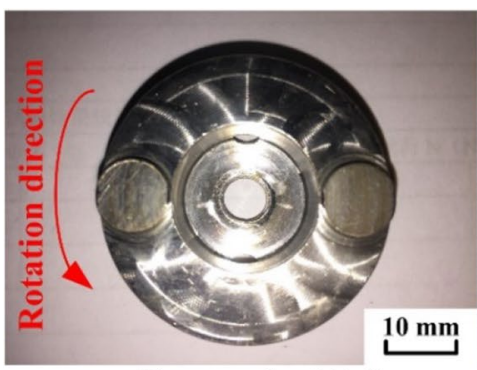

a Photograph of 316L

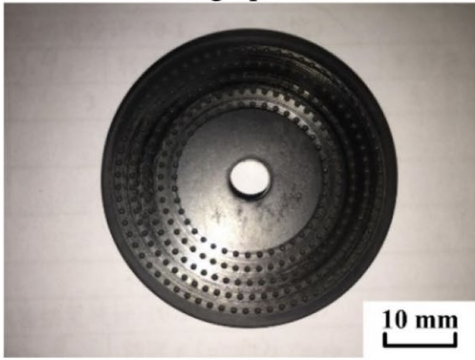

d Photograph of CF/PEEK

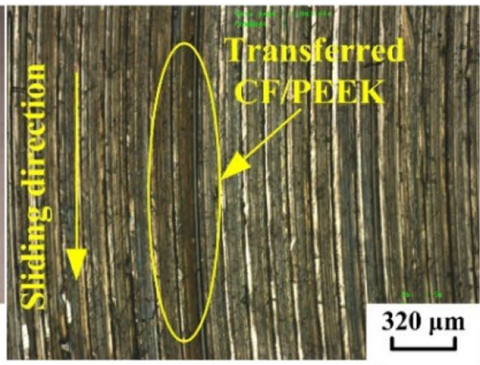

b LCM image of 316I

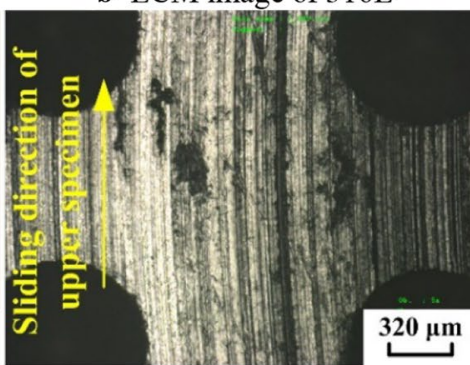

e LCM image of CF/PEEK

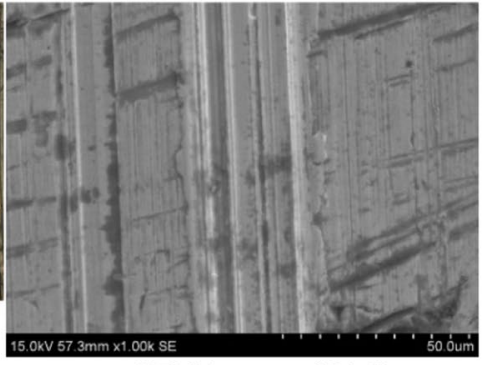

c SEM image of $316 \mathrm{~L}$

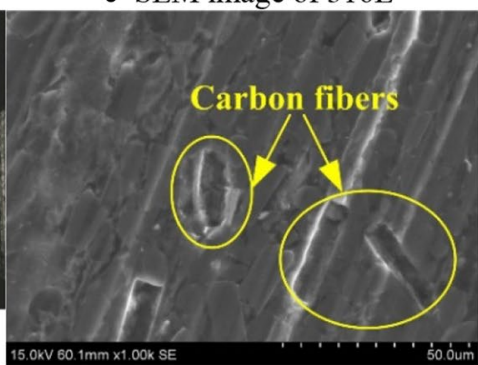

f SEM image of CF/PEEK

Figure 11 Worn surface morphology of the upper smooth-bottom with hemispherical pits friction pair

of $\mathrm{C}$. Additionally, $\mathrm{O}$ with a mass fraction of $12.87 \%$ is also obtained in the energy spectrum and indicates the occurrence of slight oxidative wear during the friction process. The fragile oxide becomes into tiny debris under friction rolling, a few parts were washed into the seawater lubricant, and a few parts that were not scoured away were captured by and pressed into the grooves on the surface of specimen. This is confirmed by the surface scanning of $\mathrm{O}$ in Figure 12(b).

The EDS analysis of the worn surface of CF/PEEK bottom specimen in Figure 13 shows that the surface material transfer caused by adhesive wear is not unidirectional. The result of element energy spectrum analysis in Figure 13(a) shows that low amounts of Fe, Mg, 


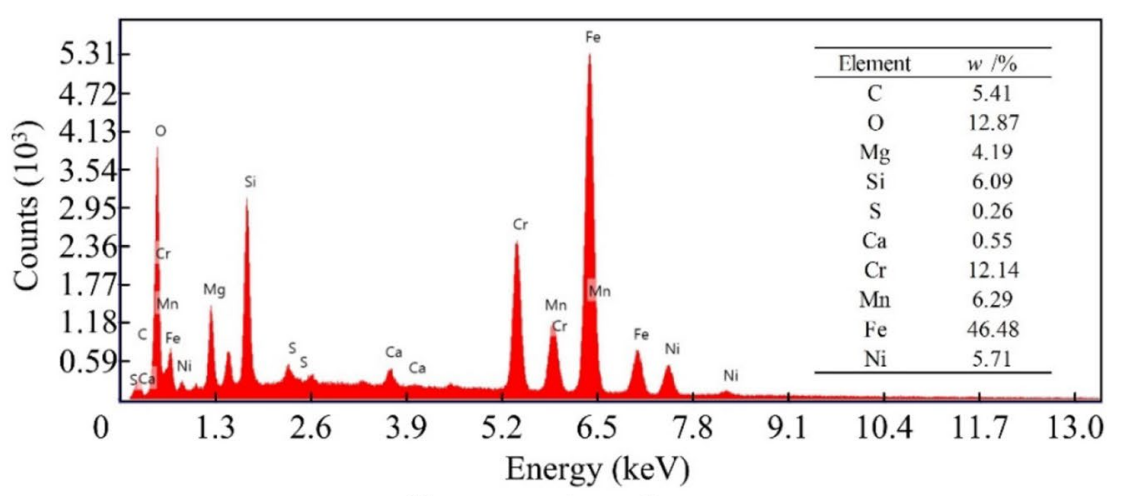

a Energy spectrum diagram

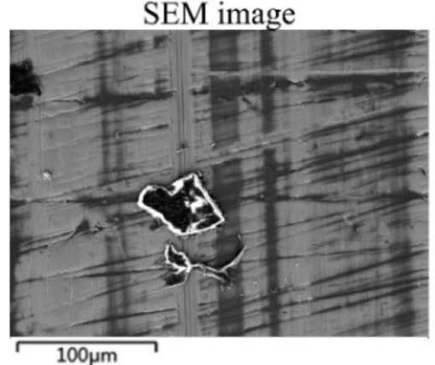

$\mathrm{Mg} \mathrm{K \alpha 1 \_ 2}$

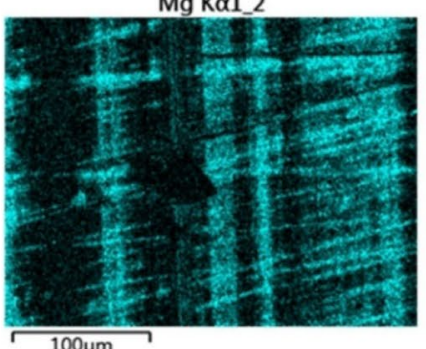

CrLa1_2

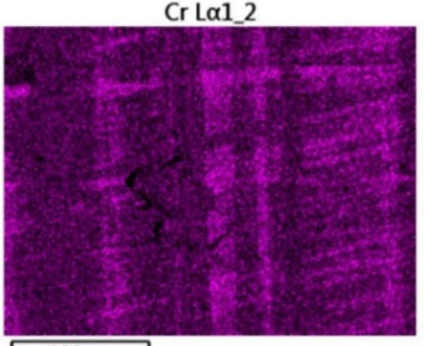

$100 \mu \mathrm{m}$

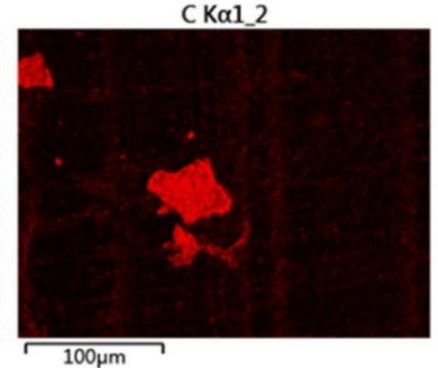

Si $K \alpha 1$

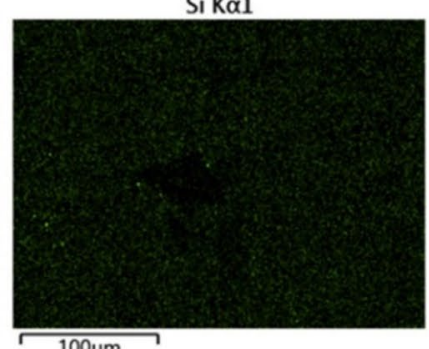

Fe $L \alpha 1 \_2$

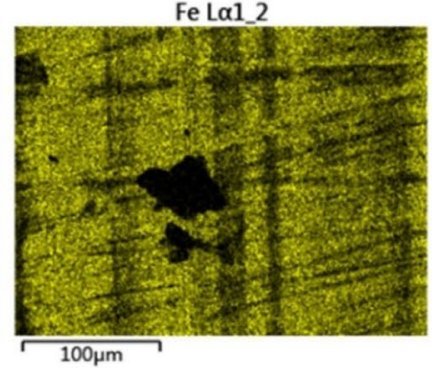

b Surface scanning diagram

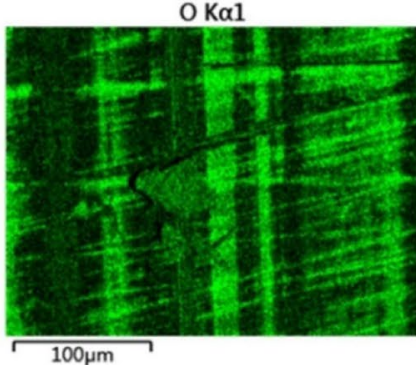

$\mathrm{S} K \alpha 1$

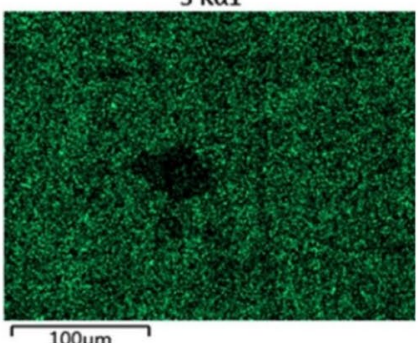

Ni La1_2

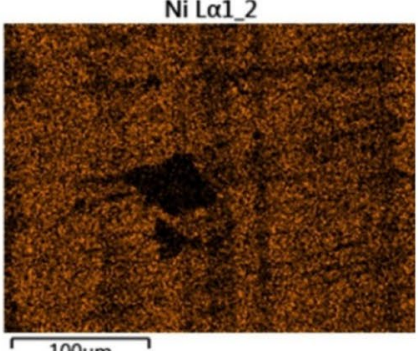

$100 \mu \mathrm{m}$

Figure 12 EDS analysis of the worn surface of 316 upper specimen

and $\mathrm{Si}$ appear on the surface of CF/PEEK after wear. The adhesion transferred to the surface of CF/PEEK is less due to the strong intermolecular bonding strength of $316 \mathrm{~L}$. This is the reason that the wear rate of bottom specimen is two orders of magnitude higher than that of upper specimen in Figure 8.
As shown as Figure 10(b) and 10(e), with respect to the smooth surface friction pair, the surface of upper specimen 316L is colored more deeply, and the grooves on the surface of bottom specimen CF/PEEK are wider and shallower. It illustrates that plowing effect is the main friction form only in the early part of the friction process, 


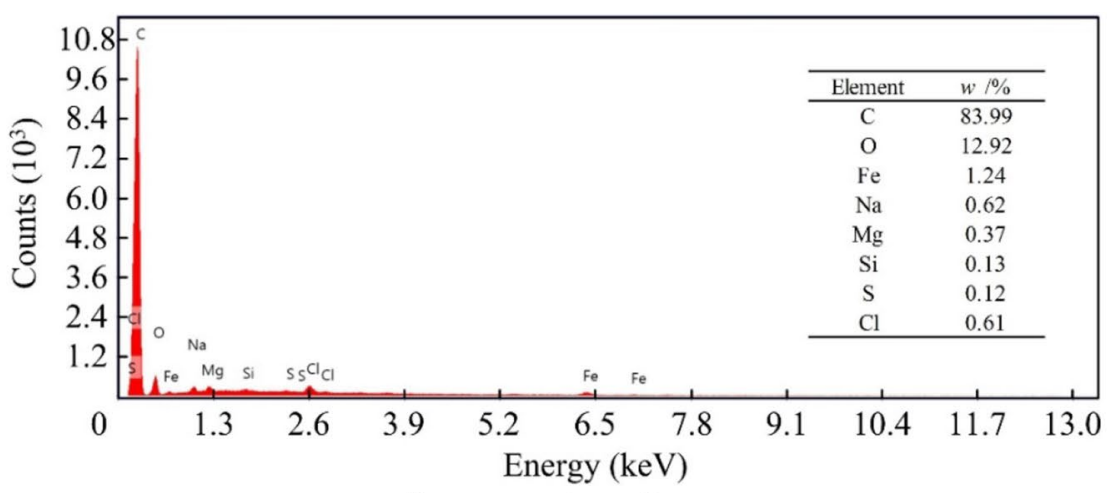

a Energy spectrum diagram
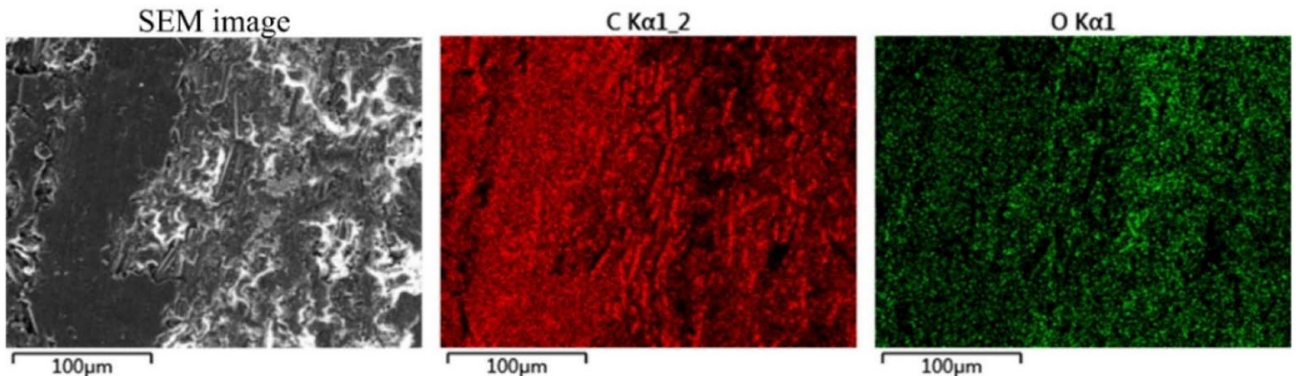

Fe La1_2

$\mathrm{Mg} \mathrm{K \alpha 12}$
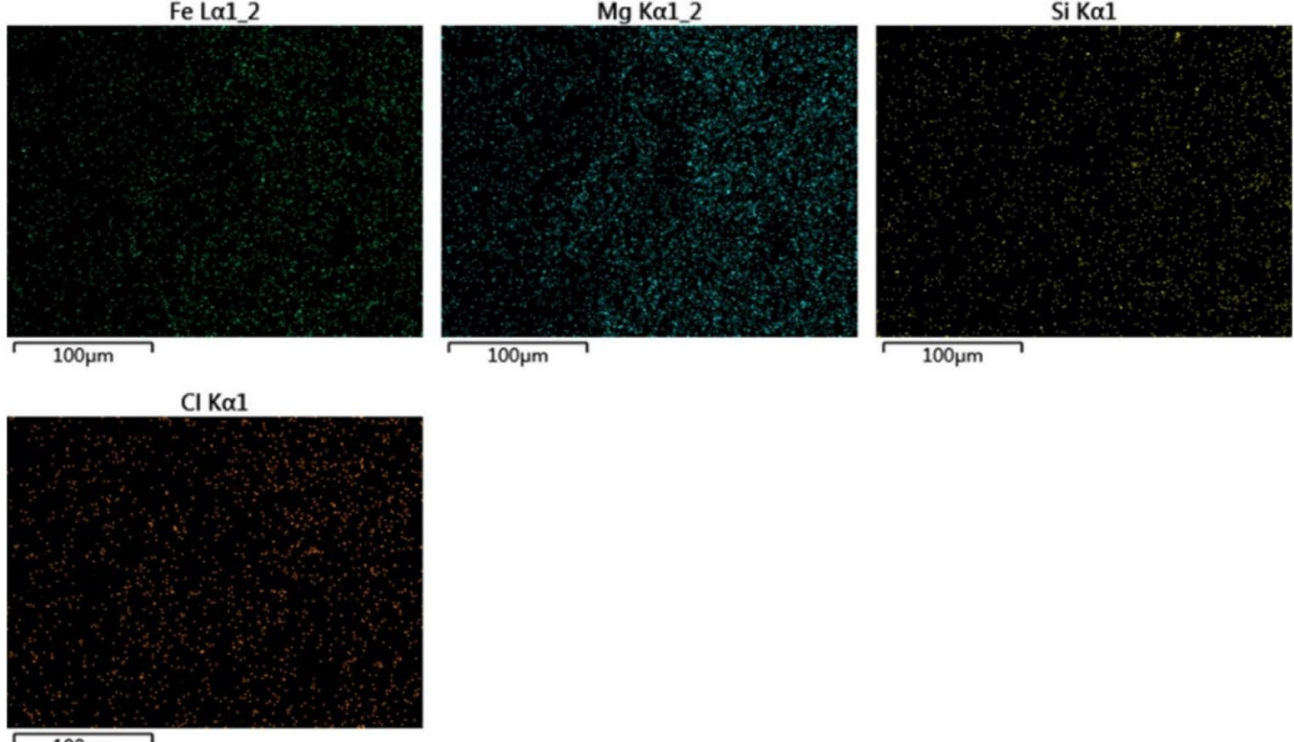

$100 \mu \mathrm{m}$

b Surface scanning diagram

Figure 13 EDS analysis of worn surface of CF/PEEK bottom specimen

and that abrasive wear and adhesive wear occupy dominant positions in the later part that caused increases in the friction coefficient, specimen temperature, and wear rate. The complete friction and wear process is exactly identical to that described in Figures 4, 6 and 8. Figure 10(d) suggests that an obvious cautery appears at the inner track of polishing ring on the smooth surface $\mathrm{CF} /$
PEEK, and this indicates that the heat generated by friction is high and the inner track exhibits bad heat dissipation. As shown in Figure 10(f), the worn surface of CF/ PEEK exhibits obvious plastic flow characteristics and the carbon fibers exposed on it are worn and fractured, and this indicates that it experienced a more intense friction movement and temperature increase. 
As shown as Figure 9(e) and Figure 11(e), with respect to the non-smooth surface friction pairs, the grooves on the surface of bottom specimen CF/PEEK are narrower and deeper. In combination with Figure 4, after a running-in period of approximately $200 \mathrm{~s}$, friction went into a relatively stable ploughing stage. Pits on the non-smooth surface specimens effectively store seawater and wear debris, and this produces the hydrodynamic effect [25] and reduces abrasive wear [31, 32] when the upper and bottom specimens slide relative to each other. The micro-trap for wear debris is verified by the following three aspects: (1) The black CF/PEEK material is stored in the pit of $316 \mathrm{~L}$ that is clearly visible in Figure 9(a). (2) The wear debris accumulated in the hemispherical pits and the grooves along the sliding direction on the surrounding surface are clearly visible in Figure 14. (3) As shown in Figure 15(a), 25.41\% of C and $38.72 \%$ of $\mathrm{O}$ in a pit of $316 \mathrm{~L}$ are attributed to $\mathrm{CF} /$ PEEK and oxides; as shown in Figure 15(b), 0.88\% of $\mathrm{Na}$ and $2.56 \%$ of $\mathrm{Cl}$ in a pit of CF/PEEK are attributed to crystalline salt in seawater, and $11.45 \%$ of Fe, $1.53 \%$ of $\mathrm{Mg}$ and $28.99 \%$ of $\mathrm{O}$ are attributed to $316 \mathrm{~L}$ and its oxides. Additionally, a cautery did not appear on CF/ PEEK surfaces in Figure 9(d) and Figure 11(d), and the abrasion of carbon fibers exposed in Figure 9(f) and Figure 11(f) is also less serious than that in Figure 10(f). Therefore, the friction process of non-smooth surface pair is mainly based on the ploughing phenomenon with slight adhesive wear. The friction coefficient and the specimen temperature are low, and the wear rate is low.

As shown in Figure 16, on all the specimen surfaces of three different types of friction pairs, 7 lines with equal intervals along the $x$ direction (horizontal direction) and 7 lines along the $y$ direction (vertical direction) were considered as the sampling positions of surface roughness, the $R a$ values before and after test were measured, and the histograms are shown in Figures 17, 18 , 19. It is observed that the $R a$ values of all the specimen surfaces increase after test, and this is because the plowing effect ploughed out several grooves. The $R a$ values along the $x$ direction generally exceed that along the $y$ direction, and this is because the grooves are distributed along the $y$ direction. The increased range of $R a$ value is the smooth surface friction pair > the upper with hemispherical pits-bottom smooth friction pair > the upper smooth-bottom with hemispherical pits friction pair. The results indicate that the relative movement during sliding of the smooth surface friction pair is the most intense and that the instantaneous high temperature, abrasive wear and adhesive wear leads to damage and the filling of the material surface are extremely uneven. Pits between the interfaces of non-smooth surface pairs produce hydrodynamic effect and store wear debris. The upper smooth-bottom with hemispherical pits friction pair exhibits its pits on the bottom specimen surface, and thus gravity makes it easier to store seawater and wear debris, and this leads to a mild friction process and an even worn surface.

\section{Conclusions}

The tribological mechanism and properties of 316 relative to CF/PEEK with a biomimetic non-smooth surface under a seawater lubricated condition are investigated through rotating sliding tests. The main conclusions are as follows:

1. With respect to the smooth surface friction pair, plowing effect is the main friction form only in the early part of the friction process, and that abrasive wear and adhesive wear occupy dominant positions in the later part. A higher friction coefficient $(0.05-$

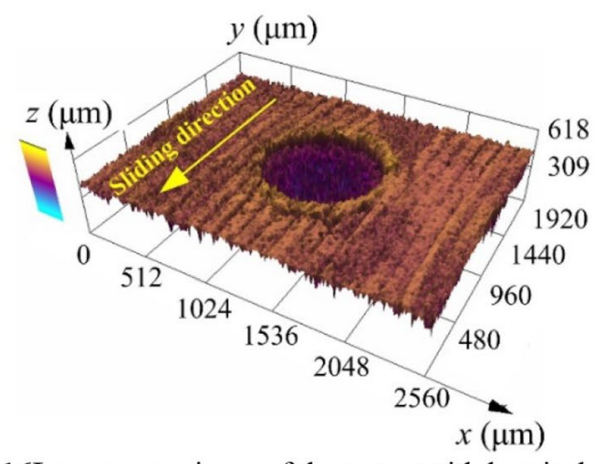

a 316L upper specimen of the upper with hemispherical pits-bottom smooth friction pair

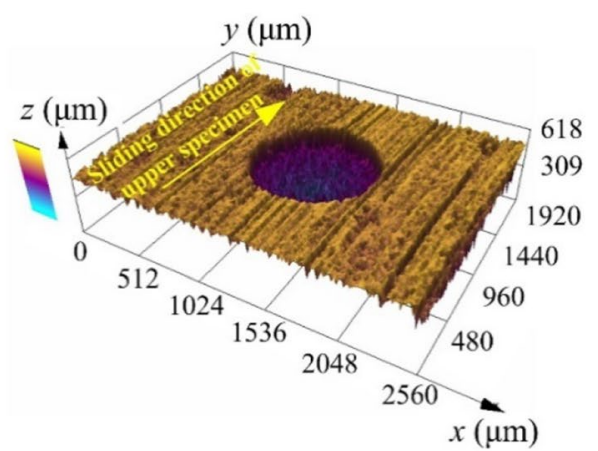

b CF/PEEK bottom specimen of the upper smooth-bottom with hemispherical pits friction pair

Figure $143 \mathrm{D}$ worn topography of the specimen with pits of non-smooth surface friction pairs 


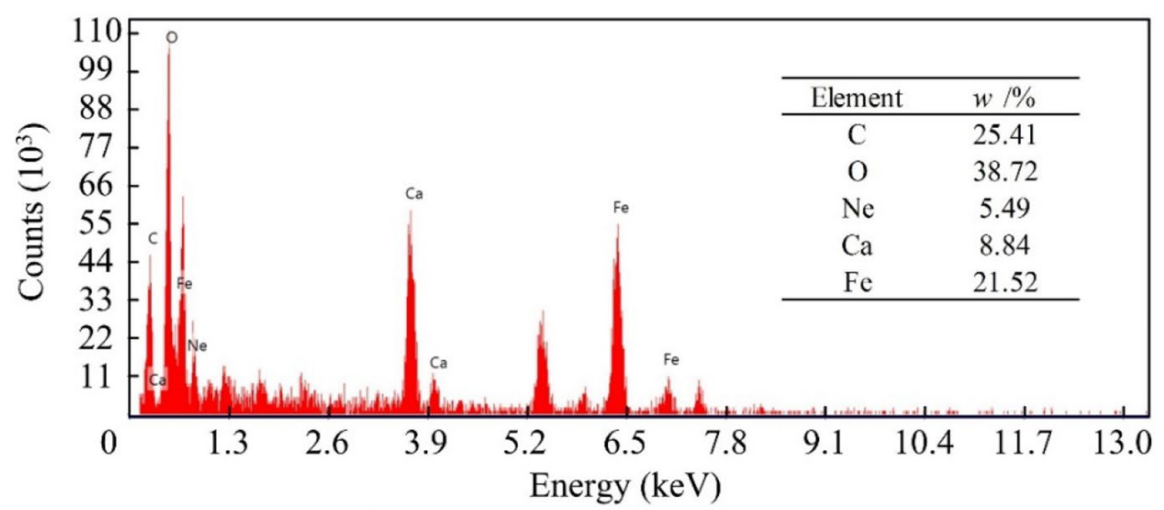

a $316 \mathrm{~L}$ upper specimen of the upper with hemispherical pits-bottom smooth friction pair

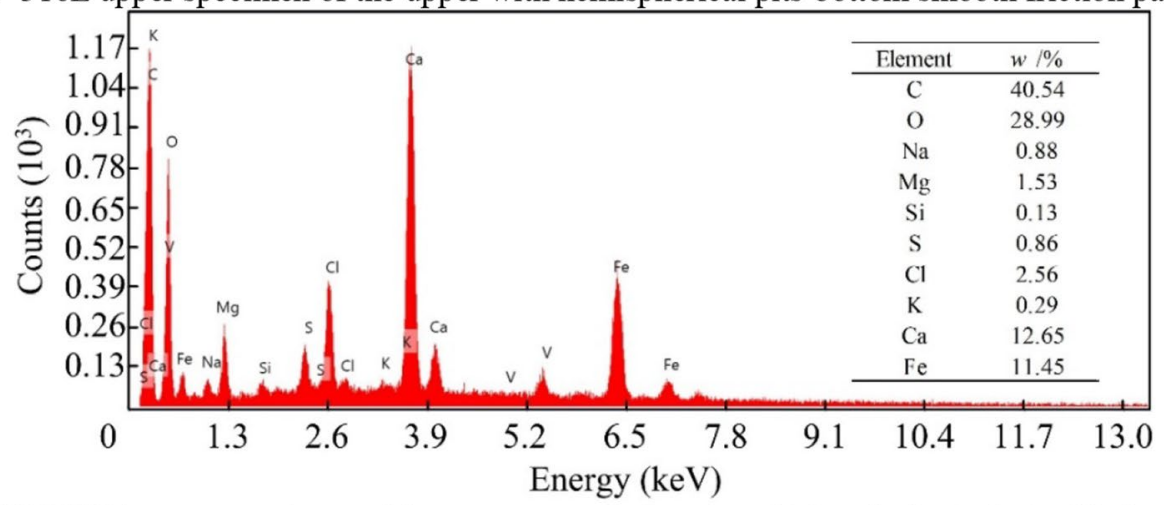

b CF/PEEK bottom specimen of the upper smooth-bottom with hemispherical pits friction pair

Figure 15 EDS of selected area in pit of non-smooth surface friction pairs'specimen after wear

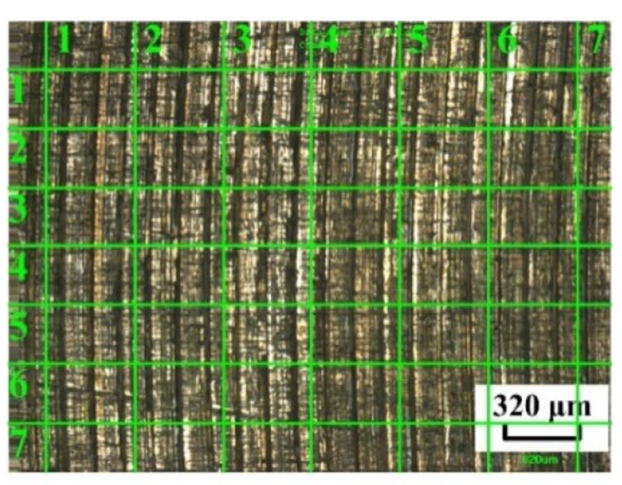

a 316L upper specimen

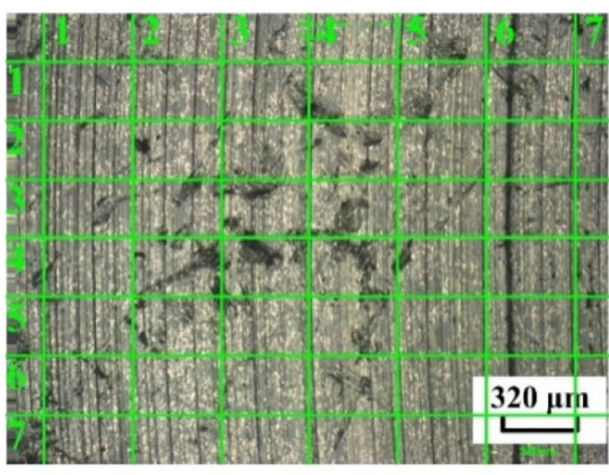

b CF/PEEK bottom specimen

Figure 16 Sampling positions of surface roughness on specimens

0.07) and specimen temperature $\left(56^{\circ} \mathrm{C}\right)$ lead to the obvious plastic flow characteristics of the CF/PEEK surface and the abrasion and fracture of the exposed carbon fibers, and thus the wear rate and surface roughness are high.
2. Pits on the non-smooth surface friction pairs effectively store seawater and wear debris, and this produces hydrodynamic effect and reduces abrasive wear, and thus plowing effect with slight adhesive wear correspond to the main friction form, that make the damage and filling of material surface are more 


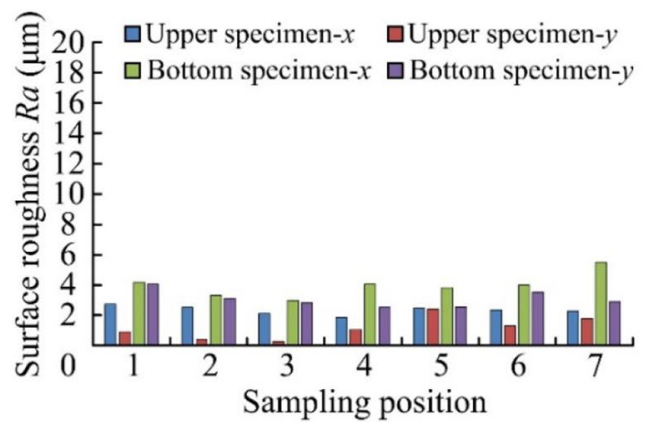

a Before the test

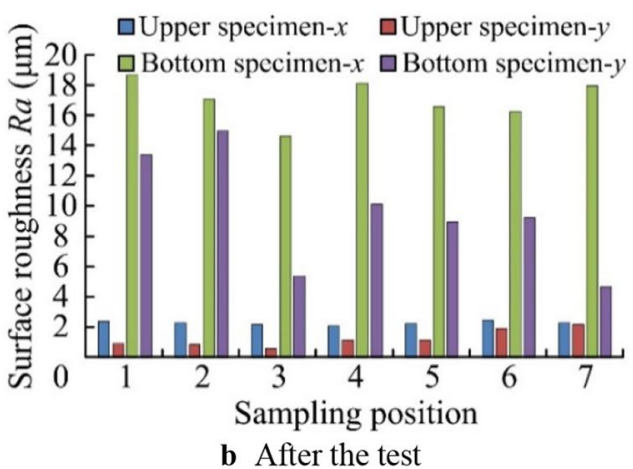

b After the test

Figure 17 Surface roughness of specimens of the upper with hemispherical pits-bottom smooth friction pair

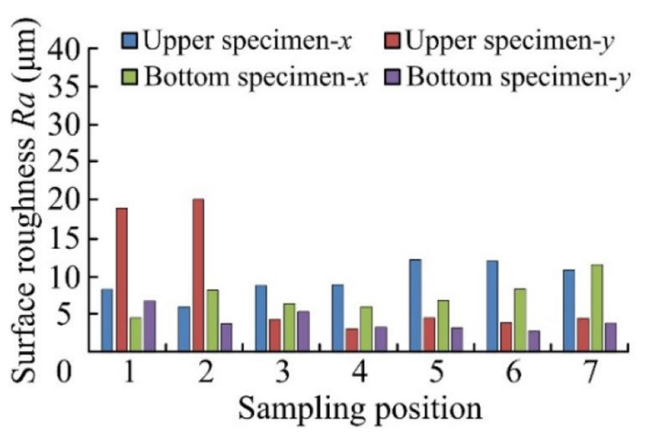

a Before the test

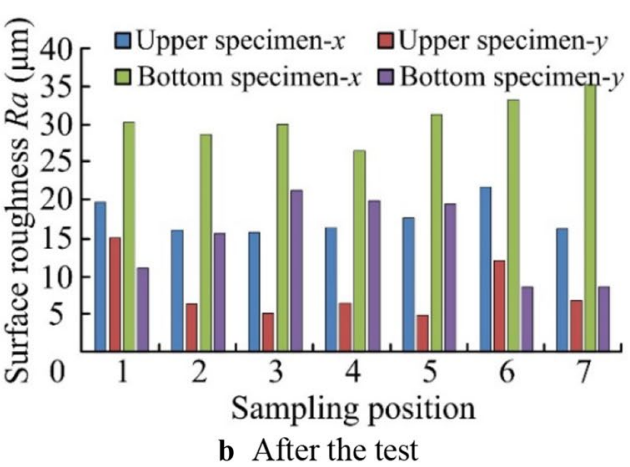

b After the test

Figure 18 Surface roughness of specimens of the smooth surface friction pair
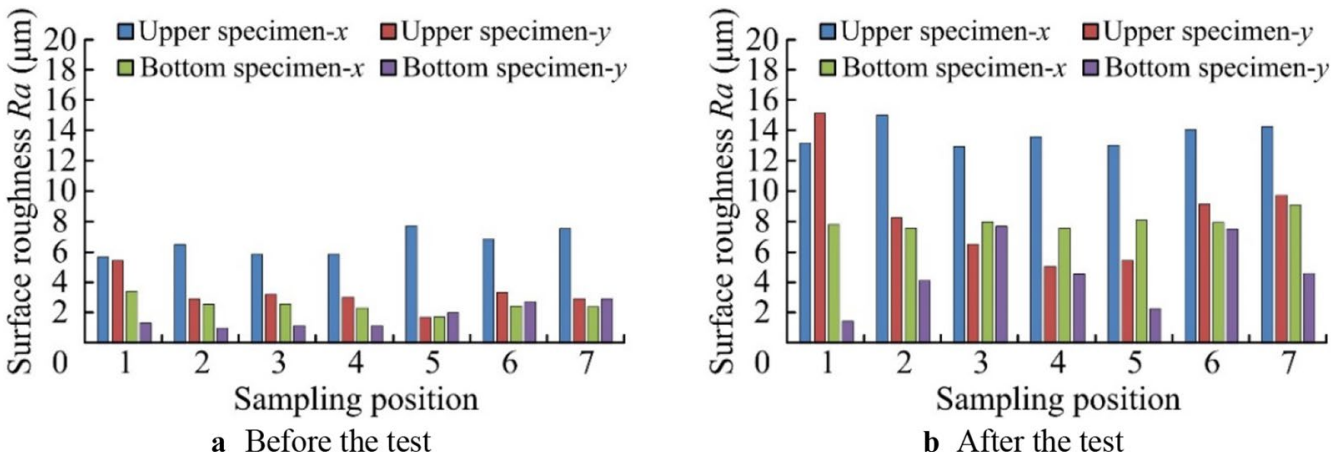

Figure 19 Surface roughness of specimens of the upper smooth-bottom with hemispherical pits friction pair

even. The friction coefficient and specimen temperature are reduced by $23 \%-25 \%$ and $7 \%-8 \%$, the wear rate of $316 \mathrm{~L}$ and CF/PEEK is reduced by $40 \%-51 \%$ and $15 \%-18 \%$, respectively, and the surface roughness is low.

3. The pits are distributed on the bottom specimen surface, and thus it is easier for the upper smoothbottom with hemispherical pits friction pair to store seawater and wear debris due to gravity, and it exhib- its the optimal effects of lubrication, drag reduction and wear resistance.

4. The surface material transfer caused by adhesive wear is bidirectional, and the wear debris and oxide are captured by and pressed into the grooves on specimen surface. The transfer film from CF/PEEK to 316L is more than that from 316L to CF/PEEK, and thus the wear rate and surface roughness of $316 \mathrm{~L}$ is less than that of CF/PEEK. 


\section{Authors' Contributions}

$D G$ and $Y L$ were in charge of the whole trial; $Y L$ wrote the manuscript; $B C$ and JZ assisted with sampling and laboratory analyses. All authors read and approved the final manuscript.

\section{Authors' Information}

Yingna Liang, born in 1982, is an associate professor at Liren College, Yanshan University, China. She received her PhD degree from Yanshan University, China, in 2018. Her research interests include CFD, PIV, biomimetic non-smooth surface, and new types of fluid components.

Dianrong Gao, born in 1962, is a professor and a supervisor of PhD candidates at School of Mechanical Engineering, Yanshan University, China. He received his PhD degree from Yanshan University, China, in 2001. His research interests include CFD, PIV, heavy machinery fluid transmission and control, and new types of fluid components and devices. He has authored two professional books and over 130 journal papers.

Bo Chen, born in 1990, is currently a PhD candidate at School of Mechanical Engineering, Yanshan University, China. His main research interests include fluid mechanics and multiphase flow.

Jianhua Zhao, born in 1983, is currently an associate professor at School of Mechanical Engineering, Yanshan University, China. He received his PhD degree from Yanshan University, China, in 2013. His research interests include the simulation and analysis of hydrostatic bearing.

\section{Acknowledgements}

The authors sincerely thank to Professor Jinku Yu of Yanshan University for his critical discussion and reading during manuscript preparation.

\section{Competing Interests}

The authors declare that they have no competing interests.

\section{Funding}

Supported by National Natural Science Foundation of China (Grant No.

51375421), Key Project of Science and Technology Plan of Higher Education of Hebei Province of China (Grant No. ZD20131027), and Youth Project of Basic Research Project of Yanshan University (Grant No. 14LGB032).

\section{Author Details}

${ }^{1}$ School of Mechanical Engineering, Yanshan University, Qinhuangdao 066004, China. ${ }^{2}$ Liren College, Yanshan University, Qinhuangdao 066004, China. ${ }^{3}$ Heibei Provincial Key Laboratory of Heavy Machinery Fluid Power Transmission and Control, Yanshan University, Qinhuangdao 066004, China.

Received: 28 May 2018 Revised: 6 January 2019 Accepted: 22 July 2019 Published online: 06 August 2019

\section{References}

[1] Shudong Yang, Shuangcheng Wu, Songlin Nie, et al. Research on applications of engineering plastics in raw water hydraulic components. China Mechanical Engineering, 2000, 11(10): 1193-1195. (in Chinese)

[2] Qunguo Tang, Zhuangyun Li, Tiehua Zhang. Application and investigation of engineering ceramics in water power components. China Mechanical Engineering, 2003, 14(8): 717-720. (in Chinese)

[3] Yinshui Liu, Zuyao Yu, Qunguo Tang, et al. Applications of surface engineering technology in water hydraulic elements. China Mechanical Engineering, 2003, 14(21): 1850-1853. (in Chinese)

[4] Zhiqiang Wang, Dianrong Gao. Friction and wear properties of stainless steel sliding against polyetheretherketone and carbon-fiber-reinforced polyetheretherketone under natural seawater lubrication. Materials and Design, 2014, 53: 881-887.

[5] Ning Li, Jianmeng Huang, Weizeng Chen. Tribological properties of PEEK WK composites under physiological saline lubrication. China Surface Engineering, 2015, 28(6): 133-140. (in Chinese)
[6] Qiang Ma, Fei Zhou, Song Gao, et al. Influence of boron content on the microstructure and tribological properties of $\mathrm{Cr}-\mathrm{B}-\mathrm{N}$ coatings in water lubrication. Applied Surface Science, 2016, 377: 394-405.

[7] M D Avilés, F J Carrión, J Sanes, et al. Effects of protic ionic liquid crystal additives on the water-lubricated sliding wear and friction of sapphire against stainless steel. Wear, 2018, 408-409: 56-64.

[8] Bo Chen, Dianrong Gao, Yingna Liang, et al. Experimental investigation of atomization and droplet turbulence characteristics of a twin-fluid nozzle with different self-excited vibrating cavity structures. Experimental Thermal and Fluid Science, 2018, 99: 525-536.

[9] D B Hamilton, J A Walowit, C M Allen. A theory of lubrication by microirregularities. Fluids Engineering, 1966, 88: 177-185.

[10] J N Anno, J A Walowit, C M Allen. Microasperity lubrication. Tribology, 1968, 90: 351-355.

[11] I Etsion, L Burstein. A model for mechanical seals with regular microsurface structure. Tribology Transactions, 1996, 39: 677-683.

[12] I Etsion. State of the art in laser surface texturing. Tribology, 2005, 127: 248-253.

[13] I Etsion. Modeling of surface texturing in hydrodynamic lubrication. Friction, 2013, 1(3): 195-209.

[14] N Tala-Ighil, M Fillon. A numerical investigation of both thermal and texturing surface effects on the journal bearings static characteristics. Tribology International, 2015, 90: 228-239.

[15] M Scaraggi, F P Mezzapesa, G Carbone, et al. Minimize friction of lubricated laser-microtextured-surfaces by tuning microholes depth. Tribology International, 2014, 75: 123-127.

[16] Luquan Ren, Zhuojuan Yang, Zhiwu Han. Non-smooth wearable surfaces of living creatures and their bionic application. Transactions of the Chinese Society for Agricultural Machinery, 2005, 36(7): 144-147. (in Chinese)

[17] Yunhong Liang, Luquan Ren. Preliminary study of habitat and its bionics. Journal of Jilin University (Engineering and Technology Edition), 2016, 46(5): 1746-1756. (in Chinese)

[18] Zhiwu Han, Luquan Ren, Zhuojuan Yang, et al. Bionic non-smooth wear gear: China, CN200510119126.1. 2006-06-28. (in Chinese)

[19] Yong Hu, Yongsheng Zhang, Zhihui Zhang, et al. Experimental study on contact fatigue resistance of bionic gears. Journal of Harbin Engineering University, 2015, 36(3): 379-383. (in Chinese)

[20] Xijun Hua, Jianguo Sun, Peiyun Zhang, et al. Research on discriminating partition laser surface micro-texturing technology of engine cylinder. Tribology International, 2016, 98: 190-196.

[21] Xijun Hua, Hongshan Xu, Yalin Chen, et al. Numerical analysis on lubrication performance of laser micro-textured roller bearings. Surface Technology, 2018, 47(3): 36-41. (in Chinese)

[22] Jinghu Ji, Yonghong Fu, Xijun Hua, et al. Tribological properties of 45 steel surface with V-grooves. China Surface Engineering, 2014, 27(4): 107-111. (in Chinese)

[23] Cong Shen, M M Khonsari. Numerical optimization of texture shape for parallel surfaces under unidirectional and bidirectional sliding. Tribology International, 2015, 82: 1-11.

[24] Cong Shen, M M Khonsari. The effect of laser machined pockets on the lubrication of piston ring prototypes. Tribology International, 2016, 101: 273-283.

[25] Yingna Liang, Dianrong Gao, Shaofeng Wu. Hydrodynamic lubrication calculation for slipper/swash plate pair with bionic non-smooth concave surface. Journal of Mechanical Engineering, 2015, 51(24): 153-160. (in Chinese)

[26] General Administration of Quality Supervision, Inspection and Quarantine of the People's Republic of China; Standardization Administration of the People's Republic of China. GB 17378.4-2007 The specifications for marine monitoring-Part 4: Seawater analysis. Beijing: Standards Press of China, 2008. (in Chinese)

[27] Shaofeng Wu, Dianrong Gao, Yingna Liang, et al. Influence of non-smooth surface on tribological properties of glass fiber-epoxy resin composite sliding against stainless steel under natural seawater lubrication. Chinese Journal of Mechanical Engineering, 2015, 28(6): 1171-1176.

[28] Qunguo Tang, Jingshen Chen, Wenhao Jin. Tribological properties of carbon fiber reinforced polyethere-therketone sliding against zirconia lubricated with water. Tribology, 2010, 30(6): 601-606. (in Chinese) 
[29] N K Myshkin, M I Petrokovets, A V Kovalev. Tribology of polymers: adhesion, friction, wear, and mass-transfer. Tribology International, 2005, 38 : 910-921.

[30] Naiming Lin, Ruizhen Xie, Junwen Guo, et al. Improvement in tribological property of 316 stainless steel via surface texturing-plasma nitriding duplex treatment. China Surface Engineering, 2016, 29(2): 58-68. (in (hinese)
[31] Shuai Zhao, Xiaolei Wang. The effects of surface texture on the wear properties of mechanical seals made of metal and polymers. Tribology, 2015, 35(6): 761-767. (in Chinese)

[32] F Saeidi, B Meylan, P Hoffmann, et al. Effect of surface texturing on cast iron reciprocating against steel under starved lubrication conditions: A parametric study. Wear, 2016, 348-349: 17-26.

\section{Submit your manuscript to a SpringerOpen ${ }^{\circ}$ journal and benefit from:}

- Convenient online submission

- Rigorous peer review

- Open access: articles freely available online

- High visibility within the field

- Retaining the copyright to your article

Submit your next manuscript at springeropen.com 